\title{
Regional Climate Change Competitiveness-Modelling Approach
}

\author{
Agnieszka Karman ${ }^{1, *(\mathbb{D})}$, Andrzej Miszczuk ${ }^{1}$ and Urszula Bronisz ${ }^{2}$ (D) \\ 1 Faculty of Economics, Maria Curie-Skłodowska University, 20-031 Lublin, Poland; \\ andrzej.miszczuk@mail.umcs.pl \\ 2 Faculty of Earth Sciences and Spatial Management, Maria Curie-Skłodowska University, \\ 20-031 Lublin, Poland; urszula.bronisz@poczta.umcs.lublin.pl \\ * Correspondence: agnieszka.karman@poczta.umcs.lublin.pl
}

Citation: Karman, A.; Miszczuk, A.; Bronisz, U. Regional Climate Change Competitiveness-Modelling Approach. Energies 2021, 14, 3704. https://doi.org/10.3390/en14123704

Academic Editors: Carla

Oliveira Henriques and

Elisabete Neves

Received: 28 May 2021

Accepted: 14 June 2021

Published: 21 June 2021

Publisher's Note: MDPI stays neutral with regard to jurisdictional claims in published maps and institutional affiliations.

Copyright: (c) 2021 by the authors. Licensee MDPI, Basel, Switzerland. This article is an open access article distributed under the terms and conditions of the Creative Commons Attribution (CC BY) license (https:/ / creativecommons.org/licenses/by/ $4.0 /)$.

\begin{abstract}
The article deals with the competitiveness of regions in the face of climate change. The aim was to present the concept of measuring the Regional Climate Change Competitiveness Index. We used a comparative and logical analysis of the concept of regional competitiveness and heuristic conceptual methods to construct the index and measurement scale. The structure of the index includes six broad sub-indexes: Basic, Natural, Efficiency, Innovation, Sectoral, Social, and 89 indicators. A practical application of the model was presented for the Mazowieckie province in Poland. This allowed the region's performance in the context of climate change to be presented, and regional weaknesses in the process of adaptation to climate change to be identified. The conclusions of the research confirm the possibility of applying the Regional Climate Change Competitiveness Index in the economic analysis and strategic planning. The presented model constitutes one of the earliest tools for the evaluation of climate change competitiveness at a regional level.
\end{abstract}

Keywords: climate change; economic; regional competitiveness; model

\section{Introduction}

The essence of competitiveness is to make time-space comparisons. It is viewed as a benchmark enabling the competitive position of an organization to be compared against that of the remaining organizations. Studies of regions' competitiveness are rooted in earlier theories of regional economy and economic geography (for review, see [1,2]) including the economic growth theory, theory of new economic geography and contemporary theories of regional development. Recommendations emerging from the theories, as well as political initiatives, offer a field for the improvement of capacity and motivation of regions for longterm economic growth, including in the sustainable development context [3]. Although a wide range of policy-related actions to improve economic results have been taken, both at the European and national levels, many challenges regions face still remain. Climate change constitutes one of such challenges. As an economic risk, global warming may pose a threat to $15 \%$ of the world's total GDP by 2050, while as a physical risk, it may contribute to a $20-30 \%$ decline in the biological diversity [4]. The Paris Agreement, signed in 2015, emphasized the importance of the socio-economic adaptation to climate change at the national and subnational level.

The diversity of the (social, economic and physical) effects of climate change, depends on the country, but also on the region. Some of the effects stem from a generalized global change, such as rising temperatures, and result in local consequences. In other cases, the change may be related to the transition to low-carbon economy. In such instances, the regional effect may be disproportionate and will not necessarily follow the global trend. Such changes can alter local conditions and affect the region's competitiveness as well.

The concept of climate change competitiveness is a part of an economic approach to competitiveness which combines economic outcomes with improved living standards and 
real income. The regional climate change competitiveness denotes the ability of a region to achieve and sustain the competitive advantage and attain economic and social development under climate change constraints when compared with other regions in the process of development. This concept is the extension of regional competitiveness, taking into account the region's impact on climate change and the region's adaptive activities. Throughout the past 20 years, scholars have studied climate change competitiveness issues from three main perspectives. The first is the relationship between climate policy and competitiveness. Aldy and Pizer [5] propounded a model discussing the impact of energy prices (being a tool of environmental protection policy) on production and net imports. Similarly, Ward et al. [6] estimated how the prices of the final output would respond to the introduction of a global carbon price. The second perspective is the relationship between the low-carbon economy and a country's competitiveness. Li, Pu and Wang [7] proposed an evaluation system based on the DPSIR model. They successively estimated low-carbon competitiveness with the TOPSIS method, and comparatively analyzed spatial differences. Wang et al. [8] offered an evaluation index system composed of 25 economic, social, environmental and policy-related indicators. The index assesses a country's policy, levels of clean energy penetration, the level of price attractiveness for clean energy deployment, investments, power sector structure and financing parameters. The third perspective focuses upon the impact of climate change on competitiveness. Srivastava et al. assess the potential for profit acquisition from the conversion to low-carbon products and processes. They highlight the ability to maintain market share (measured by existing comparative advantages) and the most convenient starting point (measured by the current output and scale). According to Flachenecker [9], material productivity can support competitiveness and serve the achievement of mitigation goals.

The Climate Competitiveness Index [10] constitutes a comprehensive system for the assessment of climate change competitiveness at a national level. The index is a metric that analyses low-carbon leadership, performance and accountability. This index shows the performance of 95 countries in relation to the pursuit of a low-carbon economy. It takes into account, inter alia, the volume of greenhouse gas reduction, the generation of new jobs, technological innovation and creation of business opportunities. Meanwhile, the Climate Institute of Australia and E3G (Third Generation Environmentalism) proposed a low-carbon competitiveness index which was designed to measure 19 different variables at the national level. Although certain efforts have been made to evaluate the regional competitiveness of climate change, such as those evidenced above, they are incidental in character. Previous studies have two important gaps. Firstly, they focus on national competitiveness, ignoring internal differentiation at the subnational level. This may lead to erroneous conclusions that the competitiveness of regions is tantamount to the competitiveness of a country. Secondly, the research on regions only takes into account the problem of competitiveness as a result of the transition to the low-carbon economy. Meanwhile, climate change competitiveness goes beyond low-carbon competitiveness, which focuses on gaining an advantage by reducing emissions through low-carbon technologies and products. It can be argued that a region's climate change competitiveness may be based on low-carbon innovation. However, such an approach is insufficient. From a practical point of view, the research conducted so far does not propose tools for measuring climate competitiveness, which makes it difficult for policy-makers to plan regional adaptive measures. There is still an urgent need for a more in-depth understanding of the relationship between climate change and regional competitiveness, in particular, the development of models for assessing the regional climate change competitiveness.

Given this gap in the literature, the present study aims to develop a regional climate change competitiveness evaluation method, including an index and measurement scales. The study discusses a method facilitating the evaluation of the current level of the regional climate change competitiveness. The study builds on the conceptual approach to competitiveness proposed by Cho and Moon [11] as well as the measurement methodology of the Regional Competitiveness Index (RCI) for the determination of competitiveness- 
related variables. We used a comparative and logical analysis of the concept of regional competitiveness and heuristic conceptual methods to construct the RCCCI index, which estimated the level of competitiveness of a region and its pillars in the conditions of climate change. The contribution of the present article is that it addresses the existing research gap regarding regional competitiveness. The definition and method for assessing the climate change competitiveness of the region offered in the study supplies a multi-aspect and comparable view of a region's competitiveness in relation to climate change. Secondly, it constitutes one of the earliest studies to focus on developing a method for the evaluation of the regional climate change competitiveness. Thus, the proposed model allows us to estimate the region's ability to provide, in relation to other regions, a socio-economic environment that will enable the production of goods and services in the conditions of current and future climate changes. At the same time, it allows areas requiring improvement to be identified. Finally, the method proposed in the article is conducive to promoting the development of regions under a climate change environment and to creating a new model for studying regional competitiveness.

The remaining parts of this article are organized as follows. Section 2 is devoted to the discussion of previous works on competitiveness, the impact of climate change on competitiveness, and intersections between regional competitiveness and climate change. This offers a basis for the definition of a region's climate change competitiveness. In Section 3, we presented detailed explanations serving as a reference for constructing the conceptual framework. Section 4 proposes a conceptual method for the evaluation of the index of the regional climate change competitiveness. Section 5 discusses practical applications and implications of the concept.

\section{Background of Regional Competitiveness}

Regional competitiveness is one of the levels of economic competitiveness (alongside micro and macro-economic competitiveness), which expresses the economic strength of an individual against its rivals in the global marketplace [12] (p. 564).

In order to gain an understanding of the meaning of competitiveness, one should differentiate between micro, meso and macro competitiveness. This stems from the fact that competitiveness emerges on the micro, regional or macroeconomic level.

Macroeconomic competitiveness is defined as the level at which a country, under market economy conditions, is able to deliver goods and services that meet the test of foreign competition and which simultaneously maintain and go beyond the domestic real income [13]. It is the ability to ensure balance concerning trade in fair and free market conditions [14]. This and other definitions indicate that macroeconomic competitiveness is related to economic outcomes that improve living standards and real income. The definitions are based on the premise concerning the existence of an open market. Some scholars (e.g., [15]) put the usefulness of the competitiveness concept into question and dispute the ability of nations to compete among themselves. However, several international studies, such as the Global Entrepreneurship Monitor, World Competitiveness Yearbook, and Global Competitiveness Report, point to the possibility of the business environment being shaped by the government, which consequently may contribute to the nation's competitiveness.

Macroeconomic competitiveness is associated with the following characteristics [16]:

1. It embraces rising living standards or real incomes as indicators of economic success.

2. It is based on the open market, where competition from foreign producers exists.

3. It points to the advantage of long-term competitiveness, which will allow favorable results to be maintained on a permanent basis.

Such an approach views competitiveness as an outcome and links it with the capacity of an economy to export or with the level of productivity [17]. As far as export is concerned, competitiveness is benchmarked against export growth. However, such a method may be unreliable (manipulation of the exchange index). According to Krugman, export capacity expresses comparative competitiveness instead of absolute competitiveness. Every country 
manifests such competitiveness in relation to certain goods, but lacks the capacity in relation to other goods. On the other hand, the growth of competitiveness via the growth of productivity may occur due to labor shedding and holding wage costs down [18]. This constitutes a low-road route to competitiveness. It treats the category in terms of an outcome. The assessment of the sources of an economy's competitiveness which affect the prospective competitive position constitutes a different approach to the matter. For example, Iarossi [19] argues that competitiveness ought to be developed based on sources unique for a particular location. This reflects the high-road route where high productivity emerges from product and process innovations and investments. According to the Global Competitiveness Report 2014-2015, competitiveness constitutes a collection of investments, policies and factors determining the level of a country' productivity. The sources of regional competitiveness include human resources, capital resources, technologies, innovations, as well as factors determining the creation of the resources and their allocation such as regulations, institutional quality, and economic instruments. In such an approach, the model of competitiveness analysis is based upon the consideration of the impact of various factors upon the generation of gross national income, high wages and high living standards.

Microeconomic competitiveness is positioned below national competitiveness. It is defined as the ability to produce and sell products and services of superior quality and at lower costs when compared with domestic and international competitors. Competitiveness leads to long-term profit performance which allows for remunerating employees and providing dividends to owners [20]. On the microeconomic level, competitiveness is defined as a firm's capacity to operate in a competitive/profitable manner. A firm's competitiveness is its economic strength against its rivals in the conditions of free movement of goods, innovations and people [12]. Such a capacity stems from the delivery of goods which match market needs in terms of price and quality, which allows the company to profit and increase their market share. Conversely, macroeconomic competitiveness offers opportunities for other countries-no win/lose situation emerges. Considering the competitiveness of countries and enterprises as analogous is erroneous. Failure of an enterprise results in its liquidation. Such an outcome is impossible in relation to a country.

Regional competitiveness constitutes an interface between the micro and macro approaches. The sixth periodic report on the regions [21] (p. 10) defines regional competitiveness as a capacity to deliver goods and services that meet the terms of the international market while maintaining a high and sustainable level of income or the region's capacity to generate a relatively high level of income and employment. In relation to the RCI, it constitutes an ability of a region to offer an attractive and sustainable environment for firms and residents to live and work in. Other authors present a similar position and argue that regions' competitiveness is their capacity to attract and retain firms with stable or growing market share while maintaining or increasing standards of living for those who participate in it [22] (p. 431). Krugman [15] argues that it may well be more meaningful to talk about competitiveness at the regional level than at the national level.

Regional competitiveness is discussed as aggregated micro-competitiveness or as a derivative of national competitiveness. In the first case, it focuses on the significance of policies for the development of market conditions. It is perceived as aggregated competitiveness of companies. Such an approach is based on the premise that companies and the region have convergent objectives. Aggregated micro-competitiveness is determined by factors offering the competitive advantage (quality of business environment), including demand conditions, strategic context, and related and supporting industries [23]. According to Porter [24], regional competitiveness is primarily determined by the capacity of local enterprises to achieve superior productivity in certain sectors. A region that is more efficient (productive) will be able to attract (and retain) labor and capital from other regions. Such an influx will tend to reinforce that region's (absolute) productivity lead still further. The author believes that productivity-based competitiveness (measured as the value of goods/services delivered per unit of the national human capital and national resources) depends on the quality of the microeconomic environment (especially physical factors) and 
on the experience of enterprises (including absorption and innovation capacity). Such a point of view enables competiveness to be considered in terms of a self-propelling process in which the present factors of competitiveness (inputs) determine the prospective ones (outputs). Subsequently, the outputs transform into inputs for further cycles/processes of competitiveness. As a consequence, strategic decisions concerning a region's development ought to be based upon data regarding the region's current competitiveness and potential.

The view of regional competitiveness in terms of aggregated micro-competitiveness significantly reduces the importance of external factors, i.e., global forces the region may have no influence over, relations with other regions, and the impact of the global economy. In addition, it is not fully clear whether a company's competitive advantage automatically translates into the region's productivity or whether the productivity leads to the emergence of the competitive advantage.

The second approach, which views competitiveness as a macroeconomic derivate, stems from the argument that productivity constitutes a vital, but insufficient determinant of regional competitiveness. The productivity level may not necessarily offer a competitive advantage. Factors enabling the emergence of added value and improvement of citizens' welfare bear more significance. Kitson et al. [25] indicate that regional competitiveness must be focused on the sources and long-term growth of the region's prosperity rather than upon the restricted understanding of competitiveness viewed via the aspect of resources and market share. Consequently, it cannot be limited to the exploitation of resources, but presupposes the identification of growth potentials and constraints of the area and the strengthening of its unique combination of resources (innovation and creativity, knowledge, technology, cultural background, tolerance, social networks, trust, responsibility, etc.) in order to create healthy living conditions [26]. Tsaurkubule et al. [27] highlight that the assessment of a region's competitiveness should include one of the main parameters of the human resource development level. Similarly, de la Vega et al. [28] base competitiveness on productive capital, human capital, social and institutional capital, infrastructure and knowledge. If the region possesses technical and social resources as well as institutional assets that enhance the development of enterprises, it will also exhibit the absolute advantage. As a consequence, owing to the consolidation of resources, the regional policy may exert a considerable impact upon the advantage. In connection with these considerations, the region is viewed in the following three manners:

- Place with export specialization-where exports are the main development factor of the region;

- $\quad$ Source of increasing profits;

- Knowledge hub, extending the "new geographical economy" to include soft factors, e.g., sociological aspects.

Such views were discussed in detail by Martin [2].

When comparing competitiveness at the regional and national level, it ought to be noted that regional mechanisms serving to adjust absolute cost differences are available to a very limited extent. Consequently, low price competitiveness results in a lack of exports at exogenously determined exchange rates. Furthermore, a region may also "exit" from the market for highly mobile production factors.

As far as regions' competitiveness is concerned, several authors emphasize that, as opposed to enterprises, regions are not independent actors. They do not have full control over processes occurring in the domain. Their level of identity is lower. Their capacity does not emerge from the scaled down national economy. Their prosperity is determined by the government's macroeconomic policy (fiscal, pecuniary). On the other hand, other authors observe that regions ought to be considered as units that directly compete with one another, which are coherent and spatially separate $[29,30]$. Such authors argue that regions constitute social aggregations with specific economic structures. We are inclined to support such views. A region is a geographically separate unit, which shapes its own environment by means of political and economic instruments. This distinguishes it from 
its "neighbors". Such a distinct social, technological and institutional context is pictured as a source of external advantages.

\section{Regional Climate Change Competitiveness-Definition of the Concept}

Studies concerning competitiveness under climate change conditions tend to encompass a 10 years' perspective. They are usually limited to the subject of low-carbon competitiveness. The report titled "G20 Low Carbon Competitiveness" [10] may be considered as a pioneer study in the field. It discusses how major economies adapt to the carbon-constrained world. It defines low-carbon competiveness as the ability of one country to provide improved current and future well-being to its residents while promoting economic prosperity through the low-carbon technological progress constrained by energy and climate-related environment. $\mathrm{Li}$ [31] defined low-carbon economy competitiveness as a country's ability to attract and optimize the allocation of factors to create wealth and improve living standards. Many theoretical and empirical studies concerning lowcarbon competitiveness have been published. Ellis [32] attempted to set up the low-carbon competitiveness diagnostic for developing countries, to apply the low-carbon logic to competitiveness analysis and to summarize risks and opportunities different economic sectors face. Regional low-carbon competitiveness systems proposed by $\mathrm{Xu}$ and Yuan [33] include a low-carbon innovation system, low-carbon production system, low-carbon management system, low-carbon support system and low-carbon culture system. Chen and Zhu [34] determined the low-carbon competitiveness model, built an index system based on low-carbon productivity and economic welfare, and used C-mode theory to determine future development goals and spatial, social and technological path selection. Pan and Wang [35] identified important indicators of low-carbon competitiveness through the principal component analysis method. Catastrophe modeling to measure low-carbon competitiveness was applied by Li et al. [36]. Their verification of the model covered 17 cities in the Shandong region. Li, Pu and Wang [7] used the DPSIR model to construct indicators for assessing low-carbon competitiveness, while the assessment itself was conducted using the TOPSIS method. Yuan and $\mathrm{Xu}$ [37] offered the concept of a new index, which includes the national capacity for development under low-carbon economy and national limitations for such a development. Development capacity pertains to the capacity for national economy's growth, low-carbon technology development, and the capacity for the management of low-carbon-related issues. The limitations pertain to energy consumption and consumption growth capacity. The aforementioned studies discuss the impact of the transition to the low-carbon economy upon regional competitiveness. The studies acknowledge the fact that competitiveness is being constrained by energy, carbon emissions and the environment in the low-carbon era. What has not been established is the answer to the question concerning broad implications of climate change in regions, i.e., those not solely limited to emission reduction.

In light of the previous research on competitiveness, we define the regional climate change competitiveness as the comprehensive ability of a region to achieve and sustain the competitive advantage and attain economic and social development under climate change constraints when compared with other regions in the process of development. This definition absorbs the idea of competitiveness in the existing literature and puts more stress on climate change constraints. First, the regional climate change competitiveness is the extension and development of regional competitiveness. Certainly, it is the new pattern of regional competitiveness, which emerged as a response to new challenges generated by climate change. Second, climate change competitiveness emphasizes the constraints that stem from the GHG emission and environmental climate change (e.g., temperature growth). Such limitations are valid for any region. As a consequence, the maintenance of the upward trend despite such limitations manifests regional competitiveness. Third, the formation of climate change competitiveness relies on the optimal allocation of regional resources. The core of competitiveness is to create regional competitive advantages-ability to compete, occupy and control the market based upon regional, environmental, social and financial 
resources. Fourth, this type of competitiveness reflects, on the one hand, the region's impact on climate change (e.g., through emissions, resource productivity and size of protected areas), and on the other hand, the impact of climate change on economic sectors and on the well-being of inhabitants (e.g., number of deaths, jobs in green industries).

It should also be noted that climate change competitiveness goes beyond low-carbon competitiveness, which focuses on gaining an advantage by reducing emissions through low-carbon technologies and products. It can be argued that a region's climate change competitiveness may be based on low-carbon innovation. However, such an approach is insufficient. It requires more diversified and effective adaptive measures that allow the region to achieve a dominant economic position (in relation to other regions).

Our approach considers regional competitiveness as a cumulative outcome of various factors. The approach offers answers to the following questions: How do institutions/systems/procedures support a region's adaptation to climate change, which consolidates the region's previous competitiveness? Which sources of a region's competitive advantage may offer the basis for the region's development under climate change conditions? Which negative outcomes of climate change exert a negative impact upon a region's competitiveness?

The development of climate change competitiveness occurs in the process of evolution. The variability of the surrounding environment generates new conditions and creates a range of possible patterns of the region's prospective economic development. It offers potential new pathways of economic evolution. A region's adaptive capacity enables it to exploit opportunities supplied by the region's economy. In view of the foregoing, a higher capacity to adapt to climate change enhances competitiveness.

The measurement of regions' climate change competitiveness is linked to two groups of indexes. The first group encompasses general indexes which directly address regional competitiveness or its various domains, e.g., World Competitiveness Rankings, Global Competitiveness Index, Global Innovation Index. The second group of indexes addresses environment-protection actions, e.g., Global Green Economy Index, Global Cleantech Innovation Index, Green Growth Indicators. No competitiveness per se emerges from such indexes. However, the indexes include factors that determine it. We believe that the assessment of climate change competitiveness ought to combine the features of both these index groups.

\section{Research Method}

The present study is of a conceptual character. Therefore, research methods encompass the comparative and logical analysis of the concept of regional competitiveness (presented in the literature) and the process of development of the competitiveness index by means of heuristic conceptual methods (Figure 1).

The development of the indicator-based system for the evaluation of climate change competitiveness is composed of the following stages, which when combined, determine the index-composite indicator [23]:

1. Determination of the pillars of a region's climate change competitiveness.

2. Identification of the indicators of pillars.

3. Normalization of the values of indicators.

4. Weighting of pillars.

5. Formulation of the function of the index.

6. Analysis of robustness and sensitivity.

Stage 1 determines sub-indexes and classifies the pillars of the regional climate change competitiveness. On the basis of existing competitiveness studies discussed in Section 3, an ideal framework for the regional climate change competitiveness is proposed. It includes six sub-indexes. The reference is the well-established Regional Competitiveness Index (RCI) model, which served as the basis for this stage. Such an approach is well-grounded. However, certain variations and adaptations were considered necessary in order to address climate change. The objective of the selection of pillars from the original RCI model was 
to distinguish those which are significantly, directly and indirectly, affected by climate change. Next, based upon the review of literature and heuristic methods, additional categories (pillars) affecting regional competitiveness were identified. The proposed pillars were subject to a review by experts.The experts' evaluation was carried out using the Delphi method. The research included ten experts from different EU regions (targeted selection) dealing with the issue of the impact of climate change on the region. The effect of examining the opinions of experts was the acceptance/rejection of the pillars and indicators proposed for the model. Despite the fact that these pillars are not included in other models of regional competitiveness, we believe that the skillful application of opportunities provided by these pillars strengthens the competitiveness. The inclusion of a broad group of pillars suggests the adoption of a comprehensive approach to the assessment of climate change competitiveness.

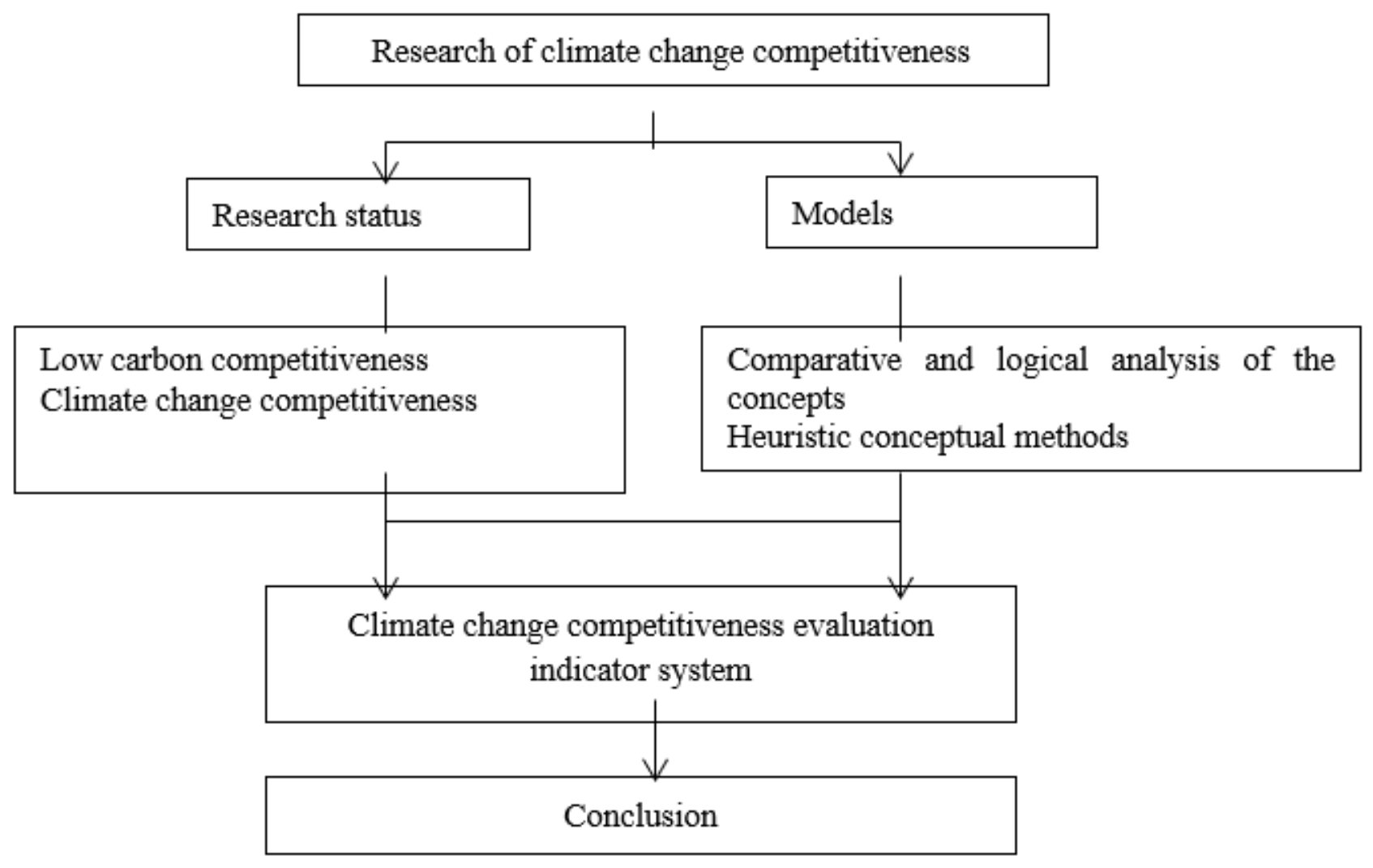

Figure 1. Research framework.

Stage 2 defines indicators specifying particular pillars. Apart from classic competitiveness indicators (from the Regional Competitiveness Index), new, additional indicators were included. Indicators illustrating the region's impact on climate change were added (e.g., carbon emissions embodied in hotels, restaurants, simplified energy balances), and the effects of the region's and sectors' climate change adaptive measures (e.g., trade in environmentally related goods, premature deaths attributable to PM 2.5, $\mathrm{NO}_{2}$ and $\mathrm{O}_{3}$ exposure) were incorporated. The following basic criteria for the initial selection of candidate indicators within each pillar were applied:

(a) Literature review concerning regional competitiveness models, low carbon competitiveness models;

(b) Experts' opinions;

(c) Balanced number of indicators across pillars.

In order to arrive at the final group of indicators (from the initial list), the multivariate analysis was used (see Section 5). In total, 89 indicators were distinguished. 
The data were extracted from a variety of sources. Examples of data sources include international organizations such as the European Environmental Agency, Eurostat, OECD and sources at the national level.

Stage 3 deals with the normalization of values of indicators defining the pillars. Due to diversified measurement units, such a normalization constitutes a crucial process of transformation. The process enables the results obtained in various units and scales to be compared with one another. The results of the normalization process may be calculated by means of the arithmetic mean and standard deviation values applied for the evaluation of the statistical population.

Stage 4 provides weight coefficients to the sub-indexes and pillars. In fact, different dimensions affect different regions in different ways. As a result, improving the competitiveness of regions which are susceptible and sensitive to climate change the most will require other priorities than those needed by the less susceptible regions. In the pillars' computation, this is reflected by a weighting system that takes into account the stage of climate change performance for the index (measured by the Climate Change Performance Index). Each sub-index was weighted differently to reflect its relevance in defining the final index on the basis of the region's CCPI value. The weights were established by a group of ten experts representing various climatic regions (Weight values depend on the value of the CCPI for the region-the RCCCI index is significantly different for the various levels of the CCPI with increasingly higher means corresponding to the increasing level of the CCPI (e.g., Innovation sub-index has a higher value in regions with higher CCPI). The weights of the individual pillars are shown in Appendix B.

A function of the index is formed in Stage 5. It assumes the following linear form (Equation (1)):

$$
\begin{gathered}
\text { RCCCI }=w_{1} \text { Basic }+w_{2} \text { Natural }+w_{3} \text { Efficiency }+w_{4} \text { Innovation }+ \\
w_{5} \text { Sectoral }+w_{6} \text { Social }
\end{gathered}
$$

where: RCCCI-regional climate change competitiveness index, Basic-result of the Basic sub-index, Natural-result of the Natural sub-index, Efficiency-result of the Efficiency sub-index, Innovation - result of the Innovation sub-index, Sectoral-result of the Sectoral sub-index, Social-result of the Social sub-index, $w_{i}$-weight coefficient of $i$ sub-index.

Values obtained in the individual sub-indexes are calculated as the arithmetic mean of pillars ascribed to these.

Stage 6 deals with the analysis of robustness and sensitivity of the index, which enables us to substantiate the robustness of the index and the transparency of the calculations.

\section{Regional Climate Change Competitiveness Index (RCCCI)}

The Regional Climate Change Competitiveness Index is a means to evaluate the ability of a region to use factors of competitiveness for the formation of a competitive position of the region under climate change conditions. The pursuit of the principle of methodological reliability, which is essential for the method of competitiveness measurement, is grounded in the analysis of the choice of competitiveness pillars featured in the literature. It is also based upon their combination into a common system, as well as upon a methodological analysis of competitiveness measured by the index. The index was designed with three objectives in mind. First of all, the index is to reflect the multi-aspect character and latent nature of competitiveness. The index estimate of the latent dimensions of competitiveness is viewed as a linear combination of the individual indicators. Secondly, the index includes the diversified weight of the sub-indexes in order to obtain the full view of competitiveness. The structure of the index stems from the premise that it constitutes a function of pillars that can be grouped into six broad sub-indexes: Basic, Natural, Efficiency, Innovation, Sectoral, and Social. In turn, each of the sub-indexes is a function of the pillars. Figure 2 shows a synoptic view of the aggregation framework followed to build the RCCCI. 


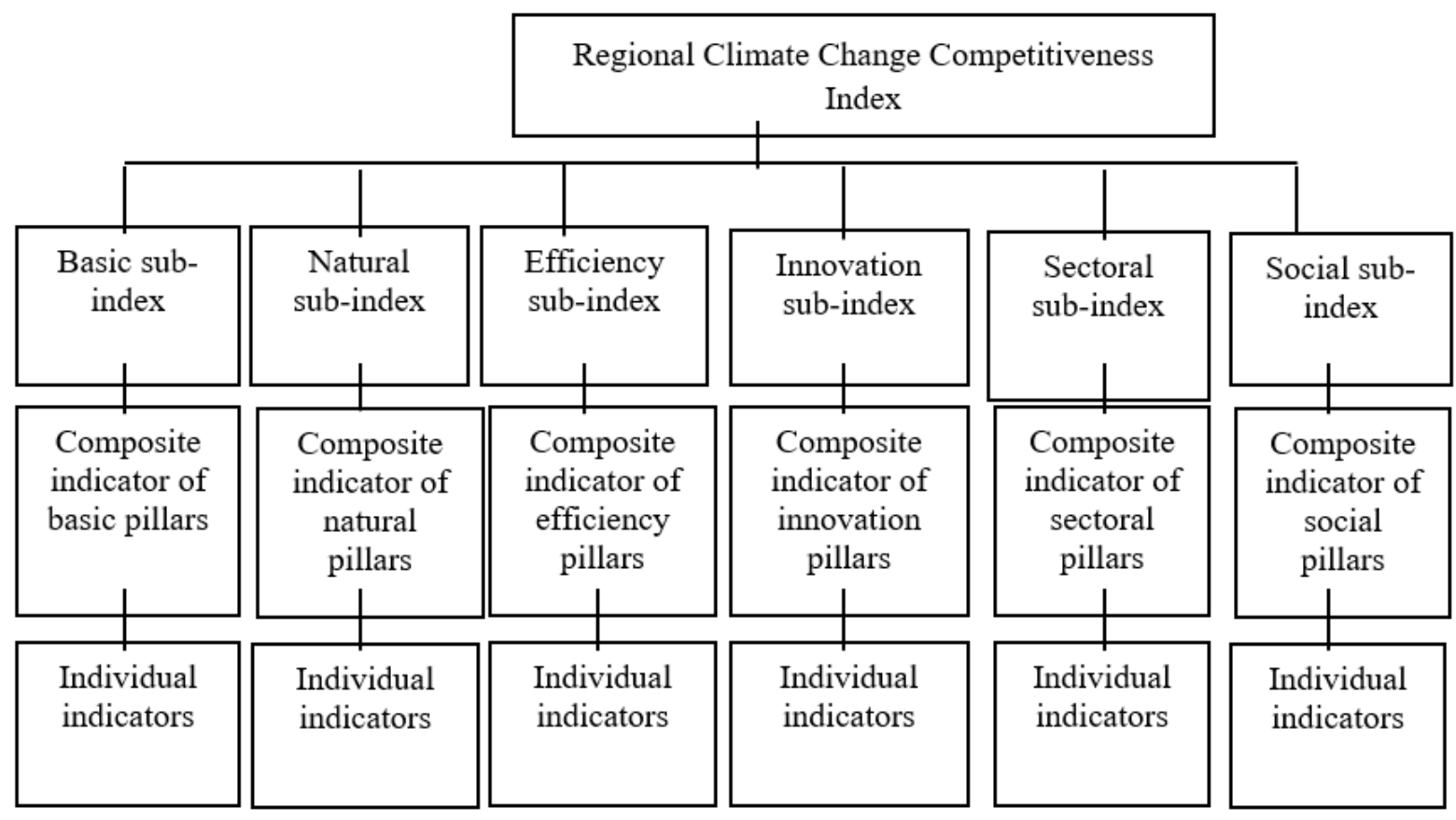

Figure 2. Synoptic view of the RCCCI.

Twenty-eight pillars were used in order to determine the main index (Table 1). In order to verify the internal consistency of the pillars, a multi-dimensional analysis and correlation analysis were performed. PCA was used for the reduction of multidimensionality. This analysis was performed for each of the pillars separately as the highlighted indicators are numerical. PCA estimated explained variance, correlation coefficients between indicators and PCA components. The results motivated the decision to exclude certain initial indicators from further analysis. Due to the considerable number of pillars included in the RCCCI model, this article presents exemplary numerical results for the selected pillars exclusively-see Appendix C.

Table 1. List of pillars with their description.

\begin{tabular}{|c|c|c|}
\hline Pillar & Description & $\begin{array}{l}\text { Number of } \\
\text { Indicators/Sub-Index }\end{array}$ \\
\hline Institutions & $\begin{array}{l}\text { The category outlines the institutional environment, especially } \\
\text { regulatory and judicial quality, level of corruption. }\end{array}$ & 3/Basic (B) \\
\hline Macroeconomic stability & $\begin{array}{l}\text { Macroeconomic stability measures the quality of general } \\
\text { economic conditions, including the regional gross domestic } \\
\text { product, resource productivity. }\end{array}$ & $4 \mathrm{~B}$ \\
\hline Infrastructure & $\begin{array}{c}\text { Tangible improvements critical for the operation of economy } \\
\text { and society. }\end{array}$ & $5 \mathrm{~B}$ \\
\hline Education & The category outlines the competences of primary school pupils. & $6 \mathrm{~B}$ \\
\hline $\begin{array}{l}\text { Institutions related to } \\
\text { climate change }\end{array}$ & $\begin{array}{l}\text { The category indicates funding opportunities for investments } \\
\text { addressing environment protection and the quality of climate } \\
\text { protection policies. }\end{array}$ & $3 \mathrm{~B}$ \\
\hline $\begin{array}{l}\text { Concentration of } \\
\text { economic entities }\end{array}$ & $\begin{array}{c}\text { Establishes the share of SMEs and mining enterprises in } \\
\text { the sector. }\end{array}$ & $2 \mathrm{~B}$ \\
\hline Water quality & Indicates water quality in the region. & 1/Natural (N) \\
\hline Air quality & Indicates air quality in the region. & $1 \mathrm{~N}$ \\
\hline Biodiversity & $\begin{array}{c}\text { Determined via the common bird index, resource productivity, } \\
\text { and forested areas. }\end{array}$ & $4 \mathrm{~N}$ \\
\hline $\begin{array}{l}\text { Effectiveness in achieving } \\
\text { climate goals }\end{array}$ & $\begin{array}{l}\text { The amount of GHG emissions reduction, RES share in total } \\
\text { energy consumption and energy efficiency. }\end{array}$ & $4 \mathrm{~N}$ \\
\hline
\end{tabular}


Table 1. Cont.

\begin{tabular}{|c|c|c|}
\hline Pillar & Description & $\begin{array}{c}\text { Number of } \\
\text { Indicators/Sub-Index }\end{array}$ \\
\hline Labor market efficiency & $\begin{array}{l}\text { Indicates structural problems in the region's economy as well as } \\
\text { the level of occupational activity. }\end{array}$ & 5/Efficiency (E) \\
\hline Market size & $\begin{array}{c}\text { Indicates the potential size of the traditional market and that of } \\
\text { the eco-friendly goods market. }\end{array}$ & $2 \mathrm{E}$ \\
\hline Economic emission intensity & $\begin{array}{l}\text { Outlines how economic growth contributes to the emission and } \\
\text { resource productivity. }\end{array}$ & $4 \mathrm{E}$ \\
\hline Resource efficiency & Issues connected with resource productivity and consumption. & $3 \mathrm{E}$ \\
\hline Technological readiness & $\begin{array}{l}\text { Outlines the level at which households and enterprises use and } \\
\text { adopt ICT solutions. }\end{array}$ & 4/Innovation (I) \\
\hline Innovativeness & $\begin{array}{l}\text { Outlines employment in science-based sectors in the region, R\&D } \\
\text { expenditures, and the number of eco-innovations. }\end{array}$ & $6 \mathrm{I}$ \\
\hline Agriculture & Outlines the impact of climate change upon crop yields. & 4/Sectoral (S) \\
\hline Tourism & $\begin{array}{l}\text { Outlines potential tourist facilities, changes in tourist trends in } \\
\text { the region, emissions generated by the sector. }\end{array}$ & $2 S$ \\
\hline Energy & $\begin{array}{c}\text { Outlines the share of renewable energy in total energy output, } \\
\text { energy productivity and the SAIDI index. }\end{array}$ & $6 \mathrm{~S}$ \\
\hline Transport & $\begin{array}{l}\text { Outlines the volume of emissions the sector is responsible for, } \\
\text { share of eco-friendly vehicles. }\end{array}$ & $4 \mathrm{~S}$ \\
\hline Industry & $\begin{array}{l}\text { Outlines the volume of emissions the sector is responsible for, } \\
\text { emissions linked with energy and heating. }\end{array}$ & $3 S$ \\
\hline Buildings & $\begin{array}{c}\text { Outlines the volume of emissions the sector is responsible for, } \\
\text { energy consumption in the sector. }\end{array}$ & $2 S$ \\
\hline Social development & Determined based on the Happy Planet Index, HDI Index. & 2/Social (Soc) \\
\hline Awareness & Outlines the way climate change is perceived. & $1 \mathrm{Soc}$ \\
\hline Attitude & $\begin{array}{l}\text { Outlines measures undertaken by individuals against } \\
\text { climate change. }\end{array}$ & $1 \mathrm{Soc}$ \\
\hline Perceived quality of life & Determined based on life satisfaction. & $1 \mathrm{Soc}$ \\
\hline Health & Outlines life expectancy, number of hospitals in the region. & $3 \mathrm{Soc}$ \\
\hline NGO power & Percentage of people employed in the sector. & $2 \mathrm{Soc}$ \\
\hline
\end{tabular}

The best way to prove the practical applicability of the proposed approach to evaluate climate change impacts on regional competitiveness based on the indicators system is to conduct a case study for a selected European region at the NUTS 2 level. Such an approach may help to illustrate the main strengths and weaknesses of this method. Thus, the next section of the article discusses the application of the RCCCI in the Mazowieckie province (central Poland).

\section{Application of the Model to the Mazowieckie Province}

This section presents the results of the competitiveness analysis for the Mazowieckie province-NUTS2 level. The choice of the region for the case study is justified by the fact that, in the light of the current paradigm of regional development, it is the most competitive region of Poland. Raw data were extracted from public databases-Eurostat, EEA, OECD as well as regional databases. Taking into account the fact that certain pieces of data for 2020 have not been published, this study collected the latest available data for each surveyed region. Our analysis encompassed 30 European regions selected randomly. Three types of problems occurred as regards raw data. First of all, indicators were presented by means of the interval scale (e.g., snow cover). As a consequence, values were attributed to intervals by means of $1-3$ codes. Secondly, negative relations emerged. Such relations denote indicators which negatively affect competitiveness (e.g., premature deaths). We assume the values of these indicators for the model with a negative sign. The third problem concerned the lack of data on the regional level with country level data available. In this case, the imputation method was adopted. The method imputes missing data by statistical 
estimates using available data. For a certain country, for region $j$ and indicator $X_{i}$, the procedure calculates the following ratio (Equation (2)):

$$
r_{i}^{j}=\frac{X_{i}^{\text {national }}}{X_{i j}^{\text {regional }}}
$$

where $X_{i}^{\text {national }}$ is the value of indicator $X_{i}$ at the country level, and $X_{i j}^{\text {regional }}$ is the value of $X_{i}$ for region $j$ in the country.

After the standardization process, raw data were converted to dimensionless values. This means that the value of each sub-index was highly comparable. As a consequence, a comprehensive evaluation was enabled. In accordance with the presented model, the standardized data reflect each region's relative position in the corresponding sub-indexes. Data for the Mazowieckie province (before standardization) are listed in Appendix A.

The values of sub-indexes were calculated as a mean value of pillars (Table 2). For the computation of the overall RCCCI index, each sub-index was weighted differently to reflect its relevance in defining the final index on the basis of the region's CCPI value. The Mazowieckie province scored "very low" on the CCPI index. Such a score reflects the situation where climate protection efforts and progress are slight. As a consequence, the level of climate change competitiveness is driven by basic socio-economic factors. It is also determined by climate-change-sensitive sectors.

Table 2. Sub-index values and weights.

\begin{tabular}{ccc}
\hline Sub-Index & Value & Weight \\
\hline Basic & 0.27 & 0.19 \\
Environmental & -0.45 & 0.16 \\
Efficiency & -0.03 & 0.15 \\
Innovation & -0.47 & 0.15 \\
Sectoral & -0.17 & 0.19 \\
Social & -0.20 & 0.17 \\
\hline
\end{tabular}

When compared with other regions, for the Basic sub-index, the Mazowieckie province scored lower in the quality of the judiciary, resource productivity, road infrastructure, climate policies, and circularity. On the other hand, it scored higher in railway infrastructure and primary education. For the Environmental and Efficiency sub-indexes, the province's results were similar to its geographic neighbors. The labor market efficiency pillar was an exception in this respect. It noted a higher number of young unemployed, lower labor productivity, and a low number of green jobs. For these indicators, mitigating measures should be taken to increase their value, which in turn positively influences the level of regional competitiveness. When compared with other regions, the Mazowieckie province is characterized by low emission from transport and construction sectors. As regards the Social sub-index, improvement is due in the public awareness of climate change and attitudes towards the issue. Statistics concerning deaths attributable to air pollution are also alarming.

The final value of the RCCCI index amounted to -0.162 (calculated according to Equation (1), Section 4), which suggests an average low level of the region's climate change competitiveness. Compared to the surveyed 30 European regions, the Mazowieckie province ranked 18th in terms of the value of the estimated index. With a decreasing ranking of regions, the index value of -0.162 indicates that the region has an average low level of the regional climate change competitiveness (the division into regions with low/high climate change competitiveness has not been rigidly quantified). 


\section{Conclusions}

The main objective of this study was to develop a regional climate change competitiveness evaluation method, including an index and measurement scales. We used a comparative and logical analysis of the concept of regional competitiveness and heuristic conceptual methods to construct the RCCCI index, which estimated the level of competitiveness of the region and its pillars in the conditions of climate change. The Mazowieckie province was used in order to verify the practical applicability of the model.

This study makes at least three contributions to the extant literature. First of all, it constitutes one of the earliest studies to focus on developing a method for the evaluation of the regional climate change competitiveness. Contrary to previous approaches, our model is not limited to the phenomenon of low emissivity, but includes a two-way impact on the climate change-regional dimension. In addition, our model goes beyond economic indicators, and takes social aspects and the physical environment into account. This model can be used to evaluate the current level of the RCCCI index, and thus help regions introduce adequate adaptive measures. Secondly, this study serves as a preliminary benchmark concerning the relationship between climate change and the economic performance of a region. It facilitates the understanding of climate change factors that may affect regional competitiveness. It utilizes an integrated index that simultaneously evaluates the impact upon the environment, society and various economic sectors. Thirdly, the model can also be employed in prospective empirical studies, especially for the purpose of evaluating regional results.

The results obtained during the theoretical and empirical research proved our model to be a convenient tool for analysis, strategic planning and information-gathering on a region. With the help of the RCCCI, the regional climate change competitiveness can be measured, the competitive position as regards other regions can be ascertained, and the change of the competitive position and the reasons of its change can be identified. The findings are also important for policymakers. The RCCCI index can be used to identify areas in need of intervention. Pillars with values lower than the average in the compared regions require mitigating measures to be introduced. These measures may focus on improving indicators that have low values within a pillar, differentiating the region from others. The identification of the weakest components of the region's climate change competitiveness should constitute the basis for defining goals for regional policy and planning initiatives/mechanisms supporting their achievement, which in the long-term will contribute to the increase of the region's competitiveness.

Despite such advantages, the method has certain limitations. The RCCCI is a static way of measurement of climate change competitiveness. It does not allow the impact of the change of one or several indicators upon the total competitiveness of the region to be precisely identified. The unknown impacts of different indicators upon the total regional competitiveness burden the formation of strategies for the improvement of competitiveness. In addition, the estimation of the RCCCI index requires a large volume of data which may not always be available at the regional level. Such limitations hinder the application of the model in regions where such data is not collected or is out of date.

Author Contributions: Conceptualization, A.K., A.M. and U.B.; methodology, A.K.; A.M. and U.B.; data curation, U.B.; writing—original draft preparation, A.K.; writing—review and editing, A.K.; All authors have read and agreed to the published version of the manuscript.

Funding: This study was funded by the National Science Centre, Poland, grant No. 2019/35/B/HS5/01548.

Institutional Review Board Statement: Not applicable.

Informed Consent Statement: Not applicable.

Data Availability Statement: The data presented in this study are available on request from the corresponding author.

Conflicts of Interest: The authors declare no conflict of interest. 


\section{Appendix A}

Table A1. Indicator values for the Mazowieckie province.

\begin{tabular}{|c|c|}
\hline Indicator & Value \\
\hline Corruption & 42.9 \\
\hline Quality of government index & 1.01 \\
\hline Regulatory quality & 79 \\
\hline Harmonized Indices of consumer prices & 108.6 \\
\hline Public debt & 45.7 \\
\hline Regional gross domestic product & 223 \\
\hline Total natural resources rents ( $\%$ of GDP) & 0.7 \\
\hline Motorways network & 104 \\
\hline Railway network & 2332 \\
\hline Population connected to wastewater treatment plants & 94.79 \\
\hline Water use in the manufacturing industry & 2.44 \\
\hline Municipal waste by waste management operations & 45.82 \\
\hline Mean score in reading (PISA) & 512 \\
\hline Mean score in math (PISA) & 516 \\
\hline Mean score in science (PISA) & 511 \\
\hline Population by tertiary educational attainment level & 43.5 \\
\hline Number of universities in the 200 best in EU & 1 \\
\hline Public expenditure on education & 11.1 \\
\hline National climate policy & 38.94 \\
\hline Investment outlays on fixed assets for air and climate protection & 0.79 \\
\hline Local government bodies which have declared climate policy & 3 \\
\hline Number of SME & 889 \\
\hline Number of enterprises in the mining and quarrying sector in the region & 29 \\
\hline Water bodies & 513 \\
\hline Air quality index & 5 \\
\hline Common farmland bird index & 79.98 \\
\hline Natural grassland $\left(\mathrm{km}^{2}\right)$ & - \\
\hline Resource productivity & 0.79 \\
\hline Woodland cover $(\%)$ & 31.5 \\
\hline Greenhouse emission gap to 2030 ESD Target & 20.9 \\
\hline Renewable energy gap to RED trajectory & 1.3 \\
\hline Energy efficiency gap to FEC & 4.2 \\
\hline Coal phase-out in long-term climate policy & 1 \\
\hline Employment rate of the 20-64 age group & 72 \\
\hline Unemployed in the youngest group (18-24) & 13.4 \\
\hline Average number of usual weekly hours of work & 41.9 \\
\hline Share of green jobs in the total number of jobs & 72 \\
\hline People employed in sensitive sectors (tourism, agriculture, energy) & 85,125 \\
\hline Disposable income of private households per inhabitant & 12,200 \\
\hline Trade in Environmentally Related Goods & 1482.76 \\
\hline Demand-based $\mathrm{CO}_{2}$ intensity & 3.73 \\
\hline Production-based $\mathrm{CO}_{2}$ intensity & 0.46 \\
\hline Consumption based $\mathrm{CO}_{2}$ emission & 0.47 \\
\hline Annual $\mathrm{CO}_{2}$ emission & 19.23 \\
\hline Circular material use rate & 9.7 \\
\hline Resource productivity & 0.75 \\
\hline Domestic material consumption per inhabitant & 1.05 \\
\hline Household level of Internet access & 83 \\
\hline Internet purchases by individuals & 52 \\
\hline Enterprises having received orders online & 11 \\
\hline Employment in technology and knowledge-intensive sectors & 146 \\
\hline Human resources in science and technology & 1659 \\
\hline Intramural R\&D expenditure & 0.45 \\
\hline Eco-innovation index & 1.03 \\
\hline
\end{tabular}


Table A1. Cont.

\begin{tabular}{|c|c|}
\hline Indicator & Value \\
\hline Product or process innovators & 0.135 \\
\hline Trademark application & 0.173 \\
\hline Innovative SMEs collaborating with others & 0.072 \\
\hline Agricultural Total Factor Productivity Index & 0.069 \\
\hline Total organic area in total cultivated area & 0.37 \\
\hline Water intensity of crop production & 9.86 \\
\hline Change in the annual number of days with rainfall & 0 \\
\hline Number of establishments and bed-places & 626 \\
\hline Nights spent at tourist accommodation establishments & $3,132,967$ \\
\hline Carbon emissions embodied in hotels, restaurants & 0.13 \\
\hline Simplified energy balances (gross available energy) & 6515.25 \\
\hline $\begin{array}{l}\text { Electricity production capacities for renewables and wastes (hydro, wind, } \\
\text { solar, solid) }\end{array}$ & 7868.26 \\
\hline Energy productivity & 4.78 \\
\hline Electricity production by auto producers & 327.72 \\
\hline System Average Interruption Duration Index (SAIDI) & 272 \\
\hline Number of residential solar PV capacity & 0.7 \\
\hline Greenhouse gas emissions in transport & 15.7 \\
\hline Newly registered electric cars in total registration & 0.004 \\
\hline Passengers of public transport (railway, maritime, air) & 34,643 \\
\hline Railway transport by maximum speed & - \\
\hline Electricity and heat emission & 55.6 \\
\hline Emission from industrial processes & 1376.83 \\
\hline Production in environmental goods & 1482.76 \\
\hline $\mathrm{CO}_{2}$ emissions from buildings & 15 \\
\hline Energy consumption (for space heating) in buildings & 14.6 \\
\hline Happy Planet Index & 27.5 \\
\hline Human Development Index & 0.88 \\
\hline Share of people treating climate change as a global problem & 70 \\
\hline Share of people taking individual action against climate change & 40 \\
\hline Life satisfaction indicator & 7.2 \\
\hline Number of hospital beds & 1060 \\
\hline Life expectancy & 77 \\
\hline Premature deaths attributable to $\mathrm{PM} 2.5, \mathrm{NO}_{2}$ and $\mathrm{O}_{3}$ exposure & 3329 \\
\hline Participation in voluntary activities & 13.8 \\
\hline People employed in the TSE sector of the total national employment & 11.1 \\
\hline
\end{tabular}

\section{Appendix B}

Table A2. Weights for sub-indexes.

\begin{tabular}{cccccc}
\hline CCPI Level & $\begin{array}{c}\text { Region-Very } \\
\text { High CCPI }\end{array}$ & $\begin{array}{c}\text { Region-High } \\
\text { CCPI }\end{array}$ & $\begin{array}{c}\text { Region-Medium } \\
\text { CCPI }\end{array}$ & $\begin{array}{c}\text { Region-Low } \\
\text { CCPI }\end{array}$ & $\begin{array}{c}\text { Region-Very Low } \\
\text { CCPI }\end{array}$ \\
\cline { 1 - 5 } Sub-Indexes & 0.16 & 0.16 & 0.17 & 0.19 & 0.19 \\
Basic & 0.16 & 0.16 & 0.16 & 0.16 & 0.16 \\
Natural & 0.21 & 0.19 & 0.19 & 0.16 & 0.15 \\
Efficiency & 0.19 & 0.19 & 0.17 & 0.18 & 0.15 \\
Innovation & 0.15 & 0.15 & 0.17 & 0.17 & 0.19 \\
Sector & 0.13 & 0.15 & $\sum 1$ & $\sum 1$ & $\sum 1$ \\
Social & $\sum 1$ & $\sum 1$ & & & \\
Sum & & & &
\end{tabular}




\section{Appendix C}

Table A3. Correlation matrix between all initial indicators for macroeconomic stability.

\begin{tabular}{cccccc}
\hline Indicators & $\begin{array}{c}\text { Harmonized } \\
\text { Indices }\end{array}$ & Public Debt & $\begin{array}{c}\text { Regional Gross } \\
\text { Domestic Product }\end{array}$ & $\begin{array}{c}\text { Total Natural } \\
\text { Resources Rents }\end{array}$ & National Savings \\
\hline $\begin{array}{c}\text { Harmonized } \\
\text { indices }\end{array}$ & 1 & $0.49(0.01)$ & $0.19(0.00)$ & $0.54(0.01)$ & $0.38(0.00)$ \\
$\begin{array}{c}\text { Public debt } \\
\text { Regional gross }\end{array}$ & $0.49(0.01)$ & 1 & $0.36(0.00)$ & $0.32(0.01)$ & $0.18(0.00)$ \\
$\begin{array}{c}\text { domestic product } \\
\text { Total natural }\end{array}$ & $0.19(0.00)$ & $0.36(0.00)$ & 1 & $0.61(0.03)$ & $-0.52(0.00)$ \\
$\begin{array}{c}\text { resources rents } \\
\text { National savings }\end{array}$ & $0.54(0.01)$ & $0.32(0.01)$ & $0.61(0.03)$ & 1 & $-0.16(0.00)$ \\
\hline
\end{tabular}

Table A4. PCA analysis for the macroeconomic stability pillar. All initial indicators: explained variance.

\begin{tabular}{cccc}
\hline \multirow{2}{*}{ Component } & \multicolumn{3}{c}{ Initial Eigenvalues } \\
\cline { 2 - 4 } & Total & \% of Variance & Cumulative \% \\
\hline 1 & 2.27 & 45.58 & 45.58 \\
2 & 1.62 & 32.47 & 78.06 \\
3 & 0.64 & 12.86 & 90.92 \\
4 & 0.24 & 4.85 & 95.77 \\
5 & 0.21 & 4.22 & 100.00 \\
\hline
\end{tabular}

Table A5. PCA analysis for the macroeconomic stability pillar. All initial indicators: correlation coefficients.

\begin{tabular}{cccccc}
\hline Indicators & \multicolumn{5}{c}{ Component } \\
\cline { 2 - 6 } & $\mathbf{1}$ & $\mathbf{2}$ & $\mathbf{3}$ & $\mathbf{4}$ & $\mathbf{5}$ \\
\hline Harmonized indices & 0.71 & 0.55 & -0.2 & -0.33 & 0.06 \\
Public debt & 0.69 & 0.33 & 0.62 & 0.02 & -0.15 \\
Regional gross domestic product & 0.75 & -0.5 & 0.12 & 0.06 & 0.33 \\
Total natural resources rents & 0.84 & -0.1 & -0.4 & 0.23 & -0.19 \\
National savings & -0.1 & 0.94 & -0.04 & 0.26 & 0.18 \\
\hline
\end{tabular}

Extraction method: PCA; five components extracted.

\section{References}

1. Vukovic, D.; Jovanovic, A.; Dukic, M. Defining competitiveness through the theories of new economic geography and regional economy. J. Geogr. Inst. Cvijic. 2012, 62, 49-64. [CrossRef]

2. Martin, R. A Study on the Factors of Regional Competitiveness; The European Commission Directorate-General Regional Policy: Cambridge, UK, 2003.

3. Gareeva, N.; Starodubova, A.; Romanova, A. The region's competitiveness assessment on the basis of "sustainable development" concept. IOP Conf. Ser. Mater. Sci. Eng. 2020, 890, 12189. [CrossRef]

4. IPCC Intergovernmental Panel on Climate Change. Managing the Risks of Extreme Events and Disasters to Advance Climate Change Adaptation; Cambridge University Press: Cambridge, UK, 2012.

5. Aldy, J.E.; Pizer, W.A. The Competitiveness Impacts of Climate Change Mitigation Policies; Discussion Paper; Harvard Kennedy School: Cambridge, MA, USA, 2015; pp. 15-73.

6. Ward, H.; Steckel, J.C.; Jakob, M. How global climate policy could affect competitiveness. Energy Econ. 2019, 84, 1-7. [CrossRef]

7. Li, J.; Pu, S.; Wang, Y. Evaluation of low carbon competitiveness of provinces and spatial differences analysis based on DPSIR -Entropy-Topsis model. J. Arid Land Resour. Environ. 2016, 30, 40-46.

8. Wang, Y.; Lan, Q.; Jiang, F.; Chen, C. Construction of China's low-carbon competitiveness evaluation system: A study based on provincial cross-section data. Int. J. Clim. Chang. Strateg. Manag. 2020, 12, 74-91. [CrossRef]

9. Flachenecker, F. Competitiveness and Climate Change Mitigation-Empirical Evidence on the Effects of Material Use and Material Productivity on Competitiveness and Greenhouse Gas. Emissions in Europe. Ph.D. Thesis, University College London, London, UK, 2018.

10. The Climate Institute. E3G G20 Low Carbon Competitiveness. 2009. Available online: http://www.e3g.org/docs/G20_Low_ Carbon_Competitiveness_Report.pdf (accessed on 15 May 2021). 
11. Cho, D.S.; Moon, H.C. From Adam Smith to Michael Porter: Evolution of Competitiveness Theory; World Scientific Publishing Co. Pte. Ltd.: Singapore, 2013. Available online: https:/ / econpapers.repec.org/bookchap/wsiwsbook/8451.htm (accessed on 20 March 2021).

12. Wang, C.-H.; Hsu, L.-C. The Influence of Dynamic Capability on Performance in the High Technology Industry: The Moderating Roles of Governance and Competitive Posture. Afr. J. Bus. Manag. 2010, 4, 562-577.

13. European Union. Sixth Periodic Report on the Regions: Summary of the Main Findings, Fact Sheet 04.02.99. 1999. Available online: https:/ / ec.europa.eu/regional_policy/sources/docgener/informat/irmo_en.pdf (accessed on 20 June 2021).

14. Djogo, M.; Stanišić, N. Is the Global Competitiveness Report the Right Measure of Macroeconomic Competitiveness. J. Econ. Bus. 2016, 34, 91-117. [CrossRef]

15. Krugman, P. Growth on the Periphery: Second Wind for Industrial Regions? The Allander Series; Fraser Allander Institute: Glasgow, UK, 2003.

16. Ketels, C. Competitiveness Frameworks Review. An. Analysis Conducted for the National Competitiveness Council; National Competitiveness Council: Dublin, Ireland, 2016.

17. Gkypali, A.; Kounetas, K.; Tsekouras, K. European countries' competitiveness and productive performance evolution: Unraveling the complexity in a heterogeneity context. J. Evol. Econ. 2019, 29, 665-695. [CrossRef]

18. Martin, R. Thinking About Regional Competitiveness: Critical Issues; Nottingham East Midlands Development Agency: Nottingham, UK, 2005.

19. Iarossi, G. Measuring Competitiveness at the Subnational Level: The Case of 37 Nigerian States (28 September 2013). J. Cent. Cathedra 2013, 6, 193-218. [CrossRef]

20. Buckley, P.J.; Pass, C.L.; Prescott, K. Measures of International Competitiveness: A Critical Survey. J. Mark. Manag. 1998, 4, 175-200. [CrossRef]

21. OECD. Competitiveness Policy: A New Agenda; DSTI/IND (95) 14, Paris, France. 1995. Available online: https: / / www.oecd.org/general/searchresults / ?q=Competitiveness\%20policy:\%20A\%20new\%20agenda.\%20DSTI/IND\%20(95 )\%20\&cx=012432601748511391518:xzeadub0b0a\&cof=FORID:11\&ie=UTF-8 (accessed on 20 March 2021).

22. Massimo, A.; Gaeta, G.; Marani, U. Similarities and Differences in Competitiveness Among European NUTS2 Regions: An Empirical Analysis Based on 2010-2013 Data. Soc. Indic. Res. 2019, 142, 431-450.

23. Snieška, V.; Bruneckienė, J. Measurement of Lithuanian Regions by Regional Competitiveness Index. Eng. Econ. $2009,1,45-57$.

24. Porter, M.E. The Competitive Advantage of Nations; Macmillan: London, UK, 1990.

25. Kitson, M.; Martin, R.; Tyler, P. Regional Competitiveness: An Elusive yet Key Concept? Reg. Stud. 2004, 38, 991-999. [CrossRef]

26. Borozan, D. Regional competitiveness: Some conceptual issues and policy implications. Interdiscip. Manag. Res. 2008, 4, 50-63.

27. Tsaurkubule, Z.; Kenzhin, Z.; Bekniyazova, D.; Bayandina, G.; Dyussembekova, G. Assessment of competitiveness of regions of the Republic of Kazakhstan. Insights Reg. Dev. 2020, 2, 469-479. [CrossRef]

28. De La Vega, S.J.C.; Buendía Azorín, J.D.; Segura, C.F.A.; Yago, E.M. A new measure of regional competitiveness. Appl. Econ. Anal. 2019, 27, 108-126. [CrossRef]

29. Bristow, G. Everyone's a “Winner": Problematising the Discourse of Regional Competitiveness. J. Econ. Geogr. 2005, 5, 285-304. [CrossRef]

30. Camagni, R.; Capello, R. Regional Competitiveness and Territorial Capital: A Conceptual Approach and Empirical Evidence from the European Union. Reg. Stud. 2013, 47, 1383-1402. [CrossRef]

31. Li, J.J. Competitiveness of Chinese Low-Carbon Economy. Ph.D. Thesis, Fujian Normal University, Fuzhou, China, 2011.

32. Ellis, K. Low Carbon Competitiveness. 2013. Available online: http://www.indiaenvironmentportal.org.in/files/file/Low\%20 carbon\%20competitiveness.pdf (accessed on 15 May 2021).

33. Xu, J.Z.; Yuan, X.L. Research on the structure of regional low-carbon competitiveness system. Sci. Technol. Prog. Policy. 2011, 28, 26-29.

34. Chen, F; Zhu, D. Research on the theory and development model of urban low carbon competitiveness. Urban. Plan. Forum. 2011, 4, 15-22.

35. Pan, W.Y.; Wang, Z.J. On low-carbon competitiveness gap evaluation of China and developed countries. J. Intell. 2013, 32, 183-190.

36. Li, C.; Huo, H.; Li, Y. Evaluation of low-carbon city competitiveness and its obstacle indicators analysis in Shandong Province. Resour. Sci. 2015, 37, 1474-1481.

37. Yuan, C.; Xu, J. China's low carbon competitiveness: An assessment based on international comparison. Int. J. Glob. Warm. 2017, 11, 390-411. [CrossRef] 